\title{
REMUNERAÇÃO DE EXECUTIVOS E INDICADORES DE DESEMPENHO: BRASIL VERSUS EUA
}

\section{EXECUTIVE COMPENSATION AND PERFORMANCE INDICATORS: BRAZIL VERSUS USA}

\section{RESUIMO}

O presente estudo busca identificar a remuneração dos executivos em relação aos indicadores de desempenho utilizados pelas empresas sediadas no Brasil e nos Estados Unidos da América. Foram analisados os relatórios de 2013 a 2016 de todas as empresas que fazem parte dos dois índices de maior relevância em ambos os países, Ibovespa e DJIA. Os resultados demonstram que não há uma fórmula ideal nem homogênea na escolha das medidas de desempenho pelas empresas. Observou-se diferenças entre os formulários de referência (Brasil) e as Proxy Statements (EUA) no que diz respeito às informações divulgadas sobre os pacotes de remuneração, tanto quanto a transparência informacional quanto a quantidade de indicadores utilizados pelas empresas. Quanto a utilização dos indicadores ao longo do tempo, notou-se que as empresas sediadas nos EUA mostram definir melhor quantos e quais indicadores utilizam no curto e no longo prazo. Por outro lado, as empresas sediadas no Brasil, no geral, não utilizam esses indicadores, dificultando assim uma comparação entre países. O estudo evidencia também maior preocupação de como são efetivamente remunerados os executivos nas empresas americanas. Sintomático assim que o mercado americano seja mais desenvolvido visto que relata mais e melhor os planos de remuneração de forma que os mesmos sejam mais claros e transparentes. Esta discrepância pode ser explicada pelo tempo que ambos os mercados vêm divulgando tais informações. Os EUA divulgam desde 1938, enquanto o Brasil passou a divulgar a partir de 2009.

Palavras-chave: Remuneração de executivos; Indicador de desempenho; Teoria da Agência.

\begin{abstract}
The present study seeks to identify executive compensation in relation to the performance indicators used by companies based in Brazil and the United States of America. Reports from 2013 to 2016 were analyzed for all the companies that are part of the two most relevant indices in both countries, Ibovespa and DJIA. The results show that there is no ideal or homogeneous formula in the choice of measures of performance by companies. Differences between the reference forms (Brazil) and the Proxy Statements (USA) were observed with respect to the information disclosed on the remuneration packages, as well as the information transparency as to the amount of indicators used by the companies. Regarding the use of indicators over time, it was noted that companies based in the United States of America show better how many and which indicators they use in the short and long term. However, companies based in Brazil, in general, do not use these indicators, making it difficult to compare countries. The study also shows greater concern about how executives are effectively remunerated in US companies. Symptomatic as soon as the American market is more developed as it reports more and better the compensation plans so that they are clearer and more transparent. This variance can be explained by the time both markets have been disclosing such information. The United States has been publishing since 1938, while Brazil has been releasing it since 2009.
\end{abstract}

Keywords: Executive Compensation; Performance Measures; Agency Theory.
Rafael Jaime de Souza

Mestrando no Programa de Pós-Graduação em Contabilidade da Universidade Federal de Santa Catarina. Graduado em Ciências Contábeis pela Universidade Federal de Santa Catarina (2013). Contato: UFSC, Centro Sócio-Econômico, Dpto de Ciências Contábeis. Campus Universitário. Trindade. 88040-500 - Florianopolis, SC. E-mail: rafael.jaime@ufsc.br

\section{Jean Carlo Rissatti}

Mestre em Contabilidade pela Universidade Federal de Santa Catarina (UFSC). Graduado em Ciências Contábeis pela Universidade Federal de Santa Catarina - UFSC. (2009-2013). Contato: UFSC, Centro Sócio-Econômico, Dpto de Ciências Contábeis. Campus Universitário. Trindade. 88040-500 - Florianopolis, SC. E-mail: rissatti.jean@gmail.com

\section{José Alonso Borba}

Doutor em Controladoria e Contabilidade pela USP (2001). Foi visiting schollar (doutorado sanduiche) na University of Illinois at Urbana-Champaign (2000-2001) Fez pós-doutoramento na HEC - Hautes Études Commerciales de Montréal, Canadá e na Rutgers University, USA (2007-2009). Professor Titular da UFSC. Contato: UFSC, Centro Sócio-Econômico, Dpto de Ciências Contábeis. Campus Universitário. Trindade. 88040-500 Florianopolis, SC. E-mail: j.alonso@ufsc.br

\section{Rogério João Lunkes} Doutor em Engenharia de Produção pela Universidade Federal de Santa Catarina (2003), Pós-Doutorado pela Universidad de Valëncia-Espanha (2011). Professor Associado III da Universidade Federal de Santa Catarina. Contato: UFSC, Centro Sócio-Econômico, Dpto de Ciências Contábeis. Campus Universitário. Trindade. 88040-970 - Florianopolis, SC E-mail: rogeriolunkes@bol.com.br 


\section{INTRODUÇÃO}

Após o aumento nos escândalos corporativos, debates acerca de transparência das informações ganharam evidência, e consequentes possíveis falhas nas práticas de remuneração dos executivos foram encontradas (BEBCHUK; FRIED, 2004). Além disso, este aumento fez com que o público tivesse maior atenção sobre o papel dos conselhos de administração em governança corporativa (GC) (LAKSMANA, 2008). Assim, a GC veio melhorar o acesso e a transparência das informações.

Nesta linha, Schiehll, Terra e Victor (2011) argumentam que um dos princípios mais aceitos de governança corporativa é que a remuneração dos executivos deve ter ligação direta com o desempenho da empresa. Assim, mecanismos como por exemplo a divulgação da remuneração dos executivos passou a ser obrigatória dentre o hall de informações divulgadas pelas empresas. No entanto, na prática as empresas estão relutantes em divulgar todos os detalhes de como estão relacionando a remuneração dos executivos com a performance organizacional (FRANTZ; INSTEFJORD; WALKER, 2013).

Esse campo tem sido alvo de investigação acadêmica e também de estudos de empresas de consultorias como a PricewaterhouseCoopers (PWC) e a Fundação Getúlio Vargas (FGV) que divulgaram em 2016 um estudo sobre a remuneração dos executivos em empresas brasileiras. Este estudo mostra que as empresas não usam indicadores eficazes que alinhe a remuneração dos seus executivos com os resultados da companhia (ARCOVERDE, 2017)

No meio acadêmico, destacam-se estudos que buscam relacionar, quantitativamente a remuneração dos executivos com algumas variáveis, como por exemplo: o tamanho da empresa, rentabilidade, participação de capital dos diretores e riqueza dos recursos do conselho (BOYD, 1996); indicadores de desempenho bem como características de governança corporativa (FUNCHAL; TERRA, 2006); a variabilidade de indicadores utilizada como medidas de performance entre setores para remunerar os executivos (DALMACIO; REZENDE; SLOMSKI, 2009); a relação com o desempenho das companhias (CONYON; HE, 2011; KRAUTER, 2013; MARÍN; SÁNCHEZ, 2003); os indicadores utilizados nas remunerações (MALVESSI; FILHO, 2016); empresas que pagam as maiores remunerações a seus executivos são as que possuem melhores resultados (AGUIAR; PIMENTEL, 2017); além da comparação entre países (CONYON; HE, 2011).

O estudo da PwC e FGV nos permite inferir que há um desalinhamento quanto a forma como os executivos são remunerados. Segundo as companhias, não são usados indicadores eficazes o suficiente para alinhar a remuneração variável de seus executivos com os resultados da companhia. No entanto, a forma como as empresas brasileiras remuneram seus executivos pode estar sendo embasada em algum outro grande mercado, como os EUA, por exemplo. Ainda, cabe o questionamento se os indicadores de desempenho utilizados em ambos os mercados são os mais alinhados com a teoria proposta pelos principais autores da área. Assim, chega-se a pergunta básica que norteia essa pesquisa: Como as empresas estão utilizando os indicadores de desempenho para remunerar seus executivos?

Para responder a esta pergunta de pesquisa, o objetivo geral da pesquisa é identificar como as empresas dos EUA e do Brasil utilizam os indicadores de desempenho para remunerar seus executivos. Desta forma, os objetivos específicos são: Identificar os percentuais das remunerações os executivos no Brasil e nos EUA; Identificar quais os indicadores de desempenho as companhias estão utilizando para remunerar seus agentes e como estão sendo distribuídos em curto e longo prazo; Verificar como estes indicadores são detalhados pelas empresas; Levantar, com base na teoria, quais ou como seriam os melhores indicadores de desempenho para se remunerar os executivos; Comparar como os países estão divulgando essas informações.

O presente estudo visa contribuir com a pesquisa sobre remuneração de executivos, principalmente na divulgação desta, a qual contribuiu com a transparência das empresas e com o fortalecimento do mercado de capitais (BEUREN; SILVA, 2015). Além do mais, evidenciar, através da comparação entre Brasil e EUA, quais indicadores de desempenho as companhias utilizam para remunerar os diretores no curto e longo prazo. Este estudo se diferencia dos demais na medida em que realiza uma comparação entre países, pois no mercado americano há a exigência das empresas divulgarem as informações de forma mais detalhada. Desta forma, busca-se comparar o Brasil com um país com um mercado estabelecido.

Por fim, quanto a estrutura, este trabalho está estruturado da seguinte forma: no capítulo 2 será abordado a fundamentação teórica, onde abordaremos os temas governança corporativa, teoria de agência, remuneração de executivos, medida de desempenho e estudos relacionados. No capítulo 3 aborda-se o procedimento metodológico. No capítulo 4 são analisados os resultados encontrados. E, por fim, no capítulo 5 a conclusão do estudo, abordando também as limitações assim como sugestões de trabalhos futuros.

\section{FUNDAMENTAÇÃO TEÓRICA}

\subsection{Governança Corporativa e Teoria de Agência}

Com o crescimento das companhias, executivos passaram a ser contratados pelos acionistas com o objetivo de comandarem e operarem as empresas. Esses executivos podem demonstrar interesses congruentes ou divergentes de seus acionistas. Nestes casos podem surgir conflitos de interesses, que com base na Teoria de Agência é o conflito entre o agente-principal, onde um é contratado para tomar as decisões em benefício do outro, que envolve delegação de certa autoridade de decisão ao agente, e que este nem sempre tomará as melhores decisões em favor daqueles (JENSEN; MECKLING,1976). 
Apontado por Murphy (2013) como a primeira linha de defesa contra os problemas de agência, o conselho de administração, eleito pelos acionistas, tem como responsabilidade monitorar, contratar, demitir e estabelecer a remuneração do CEO e dos demais executivos, sendo este último, visando o alinhamento de interesses dos CEOs interessados em risco com os acionistas. Hall (1999) sugere mitigar o problema de agência por meio do monitoramento do CEO e com a utilização de incentivos de alta potência, aproximando os pagamentos dos executivos à criação de valor aos acionistas.

Jensen, Murphy e Wruck (2004)we are in the midst of a reexamination of chief executive officer (CEO destacam que a remuneração pode tanto ser a solução para os conflitos de agência quanto um problema. Segundo os autores, os conselhos e os comitês de remuneração não estão utilizando seu próprio dinheiro, logo cria-se um problema de agência entre estes conselhos e a empresa que estão representando. Ainda, mesmo os planos mais bens planejados possuem falhas que podem ser exploradas e, em função disso executivos podem manipular o processo para benefício próprio em detrimento da empresa. Assim, como as partes possuem interesses e objetivos diferentes, chegar-se a um consenso entre estes é uma tarefa que nem todas as empresas conseguem obter.

Farid, Conte e Lazarus (2011) reiteram que a transparência pode ter papel crucial neste caso pois os acionistas podem não conseguir ter a informação que necessitam. Além disso, a estrutura de propriedade dispersa pode também contribuir para a dificuldade de monitoramento do desempenho do acionista, aumentando o problema causado pela diferença de informação.

\subsection{Remuneração de Executivos}

A remuneração de executivos, considerado uma importante ferramenta da governança corporativa, visa o alinhamento de interesses entre a companhia e seus executivos (JENSEN; MURPHY; WRUCK, 2004; KRAUTER, 2013)we are in the midst of a reexamination of chief executive officer (CEO. Existem críticas a respeito dos tamanhos das compensações que os executivos recebem, e sendo assim, existem sérios problemas com as remunerações, porém o maior problema é como os executivos são remunerados (JENSEN; MURPHY, 2010).

Segundo Conyon (2014) existe dois modelos concorrentes de remuneração de executivos que são amplamente aceitos. Um deles afirma que os salários são muito altos e os contratos são mal concebidos. A outra vertente parte do pressuposto que os contratos, apesar de não serem perfeitos, minimizam os custos de contratação que os acionistas e gestores enfrentam.

Kolb (2012) comenta que a remuneração deve ser estruturada para providenciar aos executivos incentivos adequados com o intuito de gerenciar as firmas de forma que maximize o valor da mesma. Sendo assim, essa estrutura necessariamente gera altos níveis de compensação. Hall e Liebman (1998) ressaltam a importância dos incentivos de performance dentro das empresas, pois a forma mais direta de mitigar o problema de agência é alinhando os incentivos dos executivos aos dos acionistas, no caso pacote de remuneração.

Na tentativa de assegurar uma melhor performance dos executivos, a estrutura de compensação acaba sendo elaborada em diversos componentes - salário, bônus anual, incentivos de longo prazo, ações restritas, ações por performance, opções de ações, benefícios de pensões e aposentadorias, benefícios não monetários de pós aposentadoria, além de benefícios de saúde, uso pessoal, avião corporativo (MURPHY, 2013).

Para ser atrativo o suficiente para motivar o executivo, o sistema de compensação tem como objetivos: providenciar incentivos adequados, aproximar o executivo à corporação e minimizar os custos para empresa. Além disso, visam a permanência dos executivos nas companhias, e consequentemente, minimizam os custos de contratação, treinamento e de inatividade pela posição em aberto (BALSAM, 2002).

Dentro do sistema de remuneração, destaca-se o pagamento de bônus (pagos conforme o desempenho anual) e incentivos de longo prazo (ILP), que são considerados variáveis de risco, pois se baseiam, em regra, em um ou mais indicadores de desempenho. Além de possuírem medidas e formas variadas, esses planos possuem parâmetros definidos de alvos ou limiares para pagamentos, a forma (valores monetários ou ações da companhia) e tempo de pagamento (atrelados ao desempenho acumulado dentre os últimos anos, geralmente de três ou cinco anos) (BALSAM, 2002); assim como as opções de ações que podem levar até dez anos para serem exercidas (MURPHY, 2013).

Assim, torna-se evidente que diversas características e objetivos devem ser levados em consideração na elaboração de um plano de remuneração, pois procuram maximizar o valor aos acionistas e minimizar os riscos tomados por parte da administração. Adicionalmente, tentam alcançar os objetivos a um custo mínimo aos acionistas, além disso, deve considerar as características de cada corporação e do executivo contratado. Desta forma, o contrato ideal envolve um trade-off entre alinhamento de incentivos e compartilhamento de riscos (BALSAM, 2002).

\subsection{Medida de Desempenho}

Na tentativa de aproximar os interesses entre todas as partes do alto escalão de uma companhia, os acionistas depositam o gerenciamento destas nas mãos de executivos. Estes, porém, tentam maximizar seus interesses. Assim, cabe aos diretores criarem incentivos adequados - pacotes de remuneração - aos executivos para maximizarem o valor em favor dos acionistas (EDMANS; GABAIX, 2009). Ademais, medidas de desempenho podem ajudar a criar incentivos adequados aos diretores em tomadas de decisões ótimas e intertemporais (ABERNETHY; BOUWENS; VAN LENT, 2013) 
Para Murphy (2013), levando em conta que as medidas de desempenho são imperfeitas e criam efeitos colaterais indesejáveis, o desafio está na concepção de planos de incentivos de medidas que capturem aspectos importantes das contribuições do CEO para o valor da empresa. Baker, Gibbons e Murphy (1994) expõe que uma medida de desempenho ideal consideraria tanto as externalidades estáticas em unidades de negócio quanto os efeitos dinâmicos das ações atuais sobre o valor de longo prazo, desta forma seria responsável por mostrar a contribuição de um empregado para o valor da empresa.

A combinação de três políticas básicas cria para o executivo incentivos monetários adequados com a finalidade de maximizar o valor da companhia. Algumas delas como a exigência que os CEOs se tornem proprietários de uma parcela substancial de ações da empresa e o pacote de remuneração (salário, bônus e opções de ações) podem oferecer boas recompensas por desempenhos satisfatórios e podem penalizar por fracos desempenhos além de existir a possibilidade de demissão por desempenho abaixo da expectativa (JENSEN; MURPHY, 2010).

Nesse âmbito, Agrawal e Mandelker (1987) argumentam que pode surgir problemas de incentivo gerencial, uma vez que as decisões de investimento e financiamento dos executivos são influenciadas pela consideração de riqueza pessoal. Assim, Balsam (2002) ressalta que a propriedade por parte dos executivos mitiga os conflitos e alinha os interesses entre acionistas e executivos, pois ao se tornarem acionistas possuem interesse em aumentar o preço da ação da companhia.

Empresas que procuram se destacar entre seus pares necessitam de melhores resultados e pessoas que corram riscos maiores para obterem melhores resultados, sendo assim as companhias que remuneram com base em performance atraem executivos mais criativos. Assim, criar melhores incentivos pode-se dizer que significa aumentar o risco financeiro que os CEOs enfrentaram (JENSEN; MURPHY, 2010).

Kolb (2012) e Ellig (2007) descrevem que as medidas de desempenho é um dos fatores mais críticos na construção de um sistema de bonificação, pois deve-se ter medidas externas e internas. Adicionalmente, as medidas podem ser quantitativas - financeiras e não financeiras.

Os incentivos internos incluem os recursos humanos e as políticas de compensação, além de ser um dos fatores mais importantes que podem afetar o comportamento organizacional (BAKER; JENSEN; MURPHY, 1988). Quando externas, Murphy (2001) diz que são diretamente afetadas pelas ações de gerenciamento no ano atual ou anterior, enquanto as internas são menos facilmente afetadas. Mostram ainda, que companhias optam por padrões externos quando o desempenho anterior é uma estimativa ruidosa de desempenho contemporâneo. Este gerenciamento de resultado pode ser mitigado ao se usar uma combinação de indicadores financeiros e não-financeiros na remuneração dos executivos (IBRAHIM; LLOYD, 2011).

Indicadores de desempenho são utilizados, principalmente, como componentes variáveis dos planos de compensação. Porém, as diferentes formas de pagamentos variáveis providenciam diferentes incentivos (BALSAM, 2002). Por exemplo, Murphy (2001) mostrou que a maioria das companhias escolhe padrões de desempenho com base no plano de negócios ou no orçamento das empresas, ou até mesmo no desempenho do ano anterior. Kolb (2012) diz que as medidas de desempenho mais típicas são baseadas em ganhos ou vendas. Enquanto, Murphy (2013) diz que as empresas se baseiam em medidas de lucros contábeis, como lucro líquido, lucro antes dos impostos ou lucro operacional, porém ressalta que lucros contábeis, como medidas baseadas em ações, são influenciadas por fatores que estão fora do controle do executivo, ou seja, são externas a empresa.

Neste interim, Ely (1991), Lambert e Larcker (1987) e Sloan (1993), argumentam que as análises pautadas em contabilidade impedem as flutuações que o retorno sobre ações teria pois estão fora do controle da gerência da entidade. Desta forma, são úteis nestes pacotes de remuneração.

Outra discussão são as medidas de desempenho objetivas e subjetivas. Baker et al. (1994) mostram que os contratos de incentivo geralmente incluem componentes subjetivos para mitigar as distorções causadas por incentivos objetivos imperfeitos. Assim, empresas podem utilizar medidas objetivas com avaliações subjetivas de desempenho consistente com o feedback do gerente sobre as habilidades do trabalhador, o que pode ajudar a alocar seu esforço em um próximo período (ZÁBOJNÍK, 2014).

Baker et al. (1988) descrevem que os sistemas de medidas objetivas parecem ter desvantagens perante os subjetivos, pois os funcionários podem "jogar o sistema” e assim otimizar as medidas objetivas, como as vendas e lucros. Contudo, segundo os autores, as medidas subjetivas são impopulares, uma vez que existe a falta de confiança entre as partes e a aversão a conflitos fazem com que as organizações evitem sistemas baseados em avaliações subjetivas.

Outro ponto alertado por Singh, Darwish e Potočnik (2016) é que as medidas operacionais são afetadas por um conjunto de variáveis, tanto internas quanto externas e, dessa forma, o executivo tem pouco ou nenhum controle sobre elas.

A escolha de uma medida de desempenho ou mais é relevante, uma vez que a escolha errônea pode incentivar de forma negativa ou impor riscos desnecessários ao executivo. Assim, as empresas devem considerar alguns pontos ao determinar seu pacote de remuneração, como, por exemplo, se o executivo possui uma grande quantidade de ações. Nesse caso não se sugere utilizar uma medida relacionada ao preço da ação. Ou, ainda, se a empresa está em crescimento pode querer utilizar as receitas e dar menor importância para o resultado líquido ou fluxo de caixa.

Existem diversos estudos que buscam relacionar a remuneração de executivos, porém a ligação direta entre a remuneração e indicadores de desempenho merece atenção, como mostra o Quadro 1, que traz uma síntese de estudos anteriores. 
Quadro 1 - Estudos relacionados

\begin{tabular}{|c|c|c|}
\hline Autores & $\begin{array}{l}\text { Amostra e/ou } \\
\text { Procedimentos }\end{array}$ & Resultados Gerais \\
\hline Lambert e Larcker (1987) & $\begin{array}{l}\text { Amostra de } 370 \text { empresas no perío- } \\
\text { do de } 1970 \text { a } 1984 \text {. }\end{array}$ & $\begin{array}{l}\text { As empresas atribuem um peso relativamente maior ao } \\
\text { desempenho do mercado em detrimento ao desempenho } \\
\text { contábil nos contratos de remuneração. A compensação em } \\
\text { dinheiro exibe uma forte relação positiva com o retorno so- } \\
\text { bre o patrimônio líquido, mas apenas uma relação modesta } \\
\text { com o retorno do mercado de títulos. }\end{array}$ \\
\hline Sloan (1993) & $\begin{array}{l}\text { Amostra de } 800 \text { executivos na lista- } \\
\text { gem da Revista Forbes no período de } \\
1970 \text { a } 1988 .\end{array}$ & $\begin{array}{l}\text { Examinaram o papel dos ganhos contábeis nos principais } \\
\text { contratos de remuneração dos executivos. Encontraram } \\
\text { que o salário do CEO e a compensação de bônus são mais } \\
\text { sensíveis aos ganhos nas empresas que (i) os retornos das } \\
\text { ações têm maior associação com movimentos de mercado } \\
\text { em valores patrimoniais, (ii) ganhos têm uma associação } \\
\text { mais alta com mudanças específicas de valor, e (iii) os gan- } \\
\text { hos têm uma associação menos positiva com os movimen- } \\
\text { tos do lado do mercado nos valores patrimoniais. }\end{array}$ \\
\hline Ittner, Larcker e Rajan (1997) & $\begin{array}{l}\text { Amostra de } 317 \text { empresas america- } \\
\text { nas em } 48 \text { códigos de classificação } \\
\text { industrial no período de } 1993 \text { e } 1994 .\end{array}$ & $\begin{array}{l}\text { Na média a empresa usa uma medida de desempenho } \\
\text { financeiro em seu plano de bônus. Lucro por ação, lucro } \\
\text { líquido e lucro operacional são os indicadores mais comuns. } \\
\text { Quando os bônus anuais são baseados em retornos con- } \\
\text { tábeis, o retorno sobre o patrimônio é empregado com mais } \\
\text { frequência do que o retorno sobre os ativos ou o retorno } \\
\text { sobre as vendas. }\end{array}$ \\
\hline Reichelstein (2000) & $\begin{array}{l}\text { Analisou os planos de incentivos } \\
\text { que motivam o gerente a se esforçar } \\
\text { e a investir em projetos lucrativos. } \\
\text { Utilizou medidas de desempenho } \\
\text { baseadas apenas em fluxo de caixa } \\
\text { realizado com lucro residuais. }\end{array}$ & $\begin{array}{l}\text { O lucro residual reduz o custo de agência necessário para } \\
\text { fornecer incentivos ao gerente. }\end{array}$ \\
\hline Funchal e Terra (2006) & $\begin{array}{l}\text { Amostra de } 67 \text { empresas lati- } \\
\text { no-americanas (Argentina, Brasil, } \\
\text { Chile e México) que emitiram } A D R \text { 's } \\
\text { nos EUA referente ao ano de } 2012 \text {. }\end{array}$ & $\begin{array}{l}\text { Encontraram que o desempenho econômico das grandes } \\
\text { companhias não está diretamente associado à remuneração } \\
\text { de executivos. }\end{array}$ \\
\hline Dalmacio et al.(2009) & $\begin{array}{l}\text { Amostra de } 437 \text { empresas negocia- } \\
\text { das na Bovespa no período de } 1998 \\
\text { a } 2005 \text {. }\end{array}$ & $\begin{array}{l}\text { Os resultados encontrados sugerem que, em alguns seto- } \\
\text { res específicos, os indicadores de performance podem ser } \\
\text { utilizados como parâmetros de remuneração dos gestores. }\end{array}$ \\
\hline krauter (2013) & $\begin{array}{l}\text { Amostra de } 82 \text { empresas não finan- } \\
\text { ceiras no período de } 2008 \text { e } 2009 .\end{array}$ & $\begin{array}{l}\text { Foram utilizados indicadores como: crescimento das ven- } \\
\text { das, retorno sobre o patrimônio líquido e retorno sobre ati- } \\
\text { vos. Encontraram a existência de relação significativa entre } \\
\text { a remuneração e desempenho. }\end{array}$ \\
\hline Fernandes e Mazzioni (2015) & $\begin{array}{l}\text { Amostra de } 41 \text { empresas listadas na } \\
\text { BMF\&BOVESPA para a Diretoria } \\
\text { Executiva, } 38 \text { empresas para o Con- } \\
\text { selho de Administração e } 22 \text { empre- } \\
\text { sas para o Conselho Fiscal, no perío- } \\
\text { do de } 2009 \text { a } 2011 .\end{array}$ & $\begin{array}{l}\text { As análises apontaram resultados mistos, que não per- } \\
\text { mitem uma indicação consistente sobre a existência de } \\
\text { correlação significativa entre a remuneração total dos exec- } \\
\text { utivos e o desempenho das empresas investigadas. Contu- } \\
\text { do, para a remuneração variável encontraram tendência de } \\
\text { correlações positivamente significativas. }\end{array}$ \\
\hline Bennett et al.(2017) & $\begin{array}{l}\text { Amostra com } 974 \text { empresas no } \\
\text { período de } 2006 \text { a } 2012 \text {. }\end{array}$ & $\begin{array}{l}\text { Encontraram evidências consistentes com executivos geren- } \\
\text { ciando o desempenho para atingir as metas na remuneração. }\end{array}$ \\
\hline
\end{tabular}

Fonte: elaborado pelos autores. 


\section{PROCEDIMENTOS METODOLÓGICOS}

O estudo foi realizado por meio de uma comparação qualitativa de como são remunerados os principais executivos das companhias listadas brasileiras e norte-americanas que compõe os respectivos índices da bolsa de valores de cada uma delas, IBOVESPA (Índice BOVESPA) e DJIA (Dow Jones Industrial Average). Devido ao tamanho de ambos os mercados e a falta de uma base de dados, a escolha destes dois índices foi devido à representatividade de ambos. O Ibovespa que é considerado um indicador que possui os ativos de maior representatividade e negociabilidade do mercado de ações brasileiro, e o DJIA por ser um dos índices mais acompanhado no mundo. Desta forma, a amostra é composta por 63 empresas brasileiras e 30 dos Estados Unidos da América, conforme Tabela 1.

Tabela 1 - Empresas da amostra

\begin{tabular}{|c|c|c|}
\hline EUA & \multicolumn{2}{|c|}{ BRASIL } \\
\hline $3 \mathrm{M}$ & AMBEV & JBS \\
\hline AMERICAN EXPRESS & B3 & KLABIN S/A \\
\hline APPLE & BANCO BRASIL & KROTON \\
\hline BOEING & BBSEGURIDADE & LOCALIZA \\
\hline CATERPILLAR & BR MALLS PAR & LOJAS AMERIC \\
\hline CHEVRON & BRADESCO & LOJAS RENNER \\
\hline CISCO & BRADESPAR & MAGA LUIZA \\
\hline COCA-COLA & BRASKEM & MARFRIG \\
\hline DUPONT & BRF SA & MRV \\
\hline EXXON MOBIL & CCR SA & MULTIPLAN \\
\hline GENERAL ELECTRIC & CEMIG & MULTIPLAN \\
\hline GOLDMAN SACHS & CETIP & NATURA \\
\hline HOME DEPOT & CIELO & P.ACUCAR-CBD \\
\hline IBM & COPEL & PETROBRAS \\
\hline INTEL & COSAN & QUALICORP \\
\hline JOHNSON \& JOHNSON & CPFL ENERGIA & RAIADROGASIL \\
\hline JPMORGAN & CYRELA REALT & RUMO LOG \\
\hline MCDONALD'S & ECORODOVIAS & SABESP \\
\hline MERCK\&CO & ELETROBRAS & SANEPAR \\
\hline MICROSOFT & EMBRAER & SANTANDER BR \\
\hline NIKE & ENERGIAS BR & SID NACIONAL \\
\hline PFIZER & ENGIE BRASIL & SMILES \\
\hline PROCTER\&GAMBLE & EQUATORIAL & SUZANO PAPEL \\
\hline THE TRAVELERS & ESTACIO PART & TAESA \\
\hline UNITED TECHNOLOGIES & FIBRIA & TELEF BRASIL \\
\hline UNITEDHEALTH & FLEURY & TIM PART S/A \\
\hline
\end{tabular}




\begin{tabular}{l|l|l}
\hline \multicolumn{1}{c|}{ EUA } & \multicolumn{2}{c}{ BRASIL } \\
\hline VERIZON & GERDAU & ULTRAPAR \\
VISA & GERDAU MET & USIMINAS \\
WAL-MART STORES & HYPERMARCAS & VALE \\
WALT DISNEY & IGUATEMI & VIA VAREJO \\
& ITAUSA & WEG \\
\hline
\end{tabular}

Fonte: Dados da pesquisa (2018)

Foram tabelados por meio do software Excel® os relatórios dos anos de 2013 a 2016 de cada empresa. Para o Brasil, utilizou-se o formulário de referência (FR) disponibilizado no sitio eletrônico da Bolsa e as informações necessárias foram coletadas no item 13 (Remuneração de executivos/ subitens 13.1 - política/ prática de remuneração, para os indicadores de desempenho e 13.2 - remuneração total por órgão). Já para as empresas dos EUA, analisou-se os Formulários 10K/ DEF 14A - Proxy Statements (PS), retirado do sítio eletrônico de cada uma das empresas. As informações foram coletadas no item "Compensação Executiva" (Executive Compensation). Desta forma, chegou-se ao total de 372 relatórios analisados, o que configura os dados como secundários.

Para realizar a análise foi necessário coletar dados referentes aos indicadores de desempenho e o montante da remuneração dos executivos. Para tanto, foram levantados quais os indicadores utilizados pelas empresas nesses quatro anos e classificou-se os indicadores conforme estudo de Murphy (2001), conforme Tabela 2.

Tabela 2 - Agrupamento de indicadores

\begin{tabular}{|c|c|c|}
\hline & & Exemplos \\
\hline Earnings & Ganhos & $\begin{array}{l}\text { Lucro Líquido Consolidado; Retorno Sobre Capital Investido; Rentab- } \\
\text { ilidade, etc. }\end{array}$ \\
\hline EBIT & EBIT & EBITDA operacional; Fluxo de caixa operacional; Capital de giro, etc. \\
\hline Sales & Vendas & Receita de vendas; Faturamento líquido; Receita operacional, etc. \\
\hline Indiv. Perform & Desempenho Individual & Tempo dedicado às suas funções; Trabalho em equipe; Iniciativa, etc. \\
\hline Op. Objective & Objetivos Operacionais & $\begin{array}{l}\text { Cumprimento do PMSO orçado; Custos operacionais; Cumprimento } \\
\text { de orçamento, etc. }\end{array}$ \\
\hline EVA & EVA & Valor Econômico agregado; Geração de valor = EVA/ROIC \\
\hline Strategic Goals & Objetivos Estratégicos & $\begin{array}{l}\text { Cumprimento de controles internos; Execução de investimentos; } \\
\text { Responsabilidades dos Administradores, etc. }\end{array}$ \\
\hline Cust. Satisf. & Satisfação dos clientes & Satisfação dos clientes \\
\hline Stock Price & Preço das ações & CAPEX; Valorização das ações \\
\hline Discretionary & Discricionário & ISE - Índice de Sustentabilidade Empresarial; Metas de sustentabilidade \\
\hline Safety & Segurança & Segurança do trabalho \\
\hline
\end{tabular}

Fonte: Murphy (2001)

Assim, os dados coletados foram tabelados seguindo este padrão, onde, por exemplo, caso uma remuneração estivesse ligado ao "Trabalho em Equipe" ele seria considerado com um indicador de desempenho individual.

Para efeito de comparação, a remuneração considerada foi apenas a remuneração da diretoria estatutária, uma vez que nos formulários das empresas americanas foram coletados os dados do CEO e demais executivos. A formatação da coleta foi de acordo como é evidenciado pelas empresas, e posteriormente, foi agrupado em remuneração fixa e variável.

Fez-se ainda um comparativo sobre o conteúdo apresentado por algumas empresas brasileiras e dos Estados Unidos, para fins de comparação entre o demonstrativo trazido em cada país. Por fim, com os dados coletados e padroniza- 
dos, consegue-se verificar se as empresas brasileiras seguem um padrão adotado pelas empresas dos EUA, ou seja, quais as diferenças e semelhanças entre as companhias da amostra.

\section{DISCUSSÃO DOS RESULTADOS}

Inicialmente, fez-se uma análise das informações divulgadas por cada empresa nos respectivos formulários divulgados. Notou-se que as empresas brasileiras seguem um padrão adotado pela Bolsa de Valores que especifica quais os itens mínimos que as empresas precisam divulgar. É sintomático neste sentido que todas as empresas apresentam formulários similares.

Apesar desta padronização favorecer comparações entre companhias, o que se observou são formulários, em sua maioria, com informações genéricas que agregam informação necessária, mas não suficiente ao usuário externo. Como exemplo, a Cemig informa quais indicadores - Lajida, Lucro Líquido e etc - são considerados na remuneração variável de seus executivos, sem, no entanto, explicar como esses indicadores são medidos e como são repassados aos executivos.

Outro ponto observável na maioria dos indicadores mencionados pelas empresas é que se tratam de indicadores objetivos. Esta política entra em conflito com o sugerido por Balsam (2002) que argumenta que a entidade deve também utilizar de critérios subjetivos para maximizar os efeitos do incentivo e minimizar os riscos aos executivos. Na linha sugerida pelo autor, a empresa MRV, ao menos, menciona o incentivo de longo prazo a satisfação de clientes, algo subjetivo e utilizado por 11 das 63 empresas brasileiras da amostra em 2016.

Quanto as empresas norte-americanas, nota-se que não há um padrão. Apesar disso, os relatórios divulgados por elas que trazem as informações sobre a remuneração dos executivos possuem um caráter mais informativo para seus acionistas e usuários externos de um modo geral.

Além disso, as empresas trazem a informação por membro da diretoria, ou seja, cada um dos membros nomeados tem a sua remuneração divulgada e como ela foi composta. Soma-se a isto o fato das empresas, em sua maioria, abrirem como funcionam os indicadores de desempenho e como eles são calculados, conforme Figura 1.

Figura 1 - Proxy Statement Home Depot
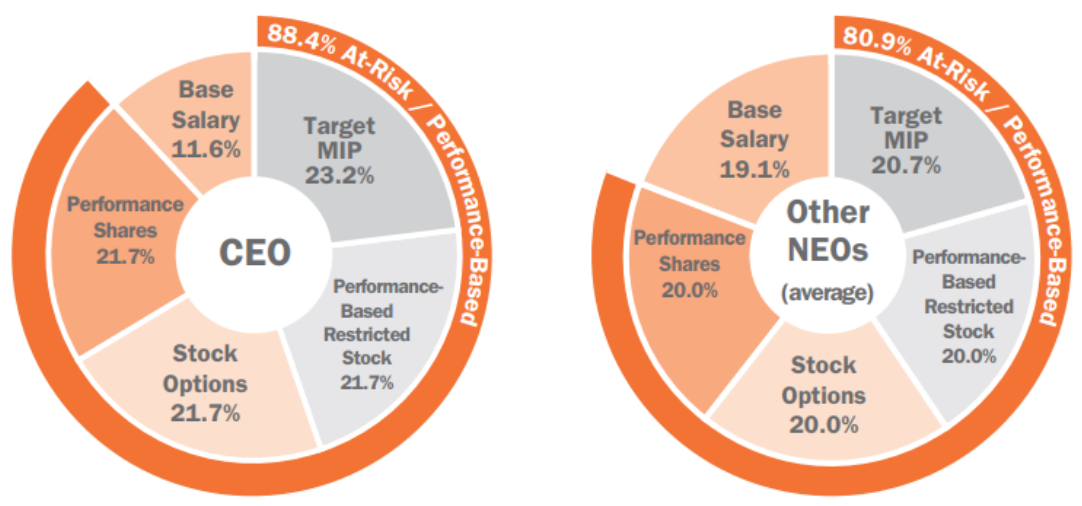

Note: Numbers may not add to $100 \%$ due to rounding

Below are the variable components of Fiscal 2016 total target compensation, including the performance measures used for each, the actual Company performance in Fiscal 2016 relevant to those measures, and the resulting compensation paid to our NEOs.

\begin{tabular}{|c|c|c|c|c|c|c|c|}
\hline \multicolumn{4}{|c|}{ Fiscal 2016 Performance Measures } & Fiscal 2016 Company Performance & \multicolumn{3}{|c|}{ Fiscal 2016 Executive Compensation Results } \\
\hline \multicolumn{8}{|c|}{ Management Incentive Plan (“MIP"): } \\
\hline \multicolumn{4}{|c|}{$\begin{array}{l}\text { Sales, operating profit and inventory turns - } \\
\text { operating profit threshold level must be met } \\
\text { for any MIP payout to occur ( } \$ \text { in billions): }\end{array}$} & \multirow{9}{*}{$\begin{array}{l}\text { Exceeded target levels for each of the sales and } \\
\text { operating profit goals and achieved performance } \\
\text { slightly below the target level for the inventory } \\
\text { turns goal: } \\
\text { - Sales (as defined in the MIP)* of } \$ 95.14 \text { billion } \\
\text { - Operating profit (as defined in the MIP)* of } \\
\$ 13.55 \text { billion } \\
\text { - Inventory turns of } 4.93 \text { times }\end{array}$} & \multirow{2}{*}{\multicolumn{3}{|c|}{$\begin{array}{l}\text { MIP payout levels are determined as a } \\
\text { percentage of base salary, with a target level } \\
\text { payout of } 200 \% \text { of base salary for the CEO, } \\
125 \% \text { for the CFO and } 100 \% \text { for other NEOs }\end{array}$}} \\
\hline & Threshold & Target $\mathrm{N}$ & Maximum & & & & \\
\hline Sales $(40 \%)$ & $\$ 89.11$ & $\$ 93.80$ & $\$ 112.56$ & & \multicolumn{3}{|c|}{ Actual MIP Payout: } \\
\hline $\begin{array}{l}\text { Operating } \\
\text { Profit }(40 \%)\end{array}$ & $\$ 11.82$ & $\$ 13.13$ & \$ 15.76 & & NEO & $\begin{array}{l}\text { Performance as } \\
\% \text { of Target }\end{array}$ & $\begin{array}{c}\text { MIP } \\
\text { Payout }\end{array}$ \\
\hline \multirow{5}{*}{$\begin{array}{l}\text { Inventory } \\
\text { Turns (20\%) }\end{array}$} & \multirow{5}{*}{4.52} & \multirow{5}{*}{5.02} & \multirow{5}{*}{6.02} & & C. Menear & $106.1 \%$ & $\$ 2,759,445$ \\
\hline & & & & & C. Tomé & $106.1 \%$ & $\$ 1,439,422$ \\
\hline & & & & & A. Campbell & $105.3 \%$ & $\$ 705,279$ \\
\hline & & & & & M. Holifield & $105.3 \%$ & $\$ 821,071$ \\
\hline & & & & & M. Carey & $106.1 \%$ & $\$ 780,074$ \\
\hline
\end{tabular}


Pode-se observar na parte superior da figura 1, que a Home Depot evidencia de forma gráfica e segregada como são estruturados os pacotes de remuneração do CEO e dos outros executivos que podem ser alcançados e divulga a porcentagem de cada elemento que compõe a remuneração. Por exemplo, o CEO recebe 11,6\% referente a salário (sem risco), enquanto a parcela "no risco" equivale a $88,4 \%$ do total; desses $65,1 \%$ são de longo prazo e apenas $23,2 \%$ de curto prazo (MIP). Em relação aos outros executivos, nota-se que recebem uma parcela maior fixa em comparação ao CEO, sendo de $19,1 \%$ e, consequentemente, recebem menores partes variáveis.

Já na parte inferior, nota-se as medidas de desempenho que foram utilizadas para remunerar no curto prazo (MIP), sendo vendas (40\%), Lucro Operacional (40\%) e giros de estoque (20\%). Para a remuneração de longo prazo, dentro da parcela de Performance Shares a companhia utilizou indicadores como média de 3 anos para retorno sobre o capital investido (50\%) e lucro operacional (50\%). Quanto ao pagamento baseado em ações restritas foi utilizado o lucro operacional. Porém, a empresa ressalta que este pagamento será perdido se o lucro operacional de 2016 não alcançar pelo menos 90\% do alvo do MIP (pelo menos U\$ 11.82 bilhões). Deve-se observar ainda que este tipo de remuneração possui o vesting period (período de aquisição) que deve ser cumprido para que o executivo tenha direito sobre as ações, que no caso é de $50 \%$ depois de 30 meses e outros 50\% depois de 60 meses da data de concessão. Para a remuneração baseada em stock options (opções de ações) utiliza-se como medida o desempenho do preço da ação e o retorno total ao acionista (TSR), que leva em consideração tanto o retorno da empresa como o retorno do índice S\&P500.

Faz-se necessário ressaltar que este tipo de remuneração também possui o período de aquisição, que neste caso, as opções são adquiridas $25 \%$ no segundo, terceiro, quarto e quinto aniversário da data de concessão.

Observa-se a disparidade entre o divulgado pelas empresas brasileiras e o divulgado pela Home Depot no exemplo acima. Essa divulgação traz uma transparência que não há entre as empresas brasileiras. Já com relação a utilização de indicadores subjetivos, não há também grande utilização, sendo que as empresas, em sua maioria, utilizam indicadores objetivos, assim como as empresas brasileiras.

Outro exemplo de empresa dos Estados Unidos que pode ser mencionada é a Dupont, que traz dados detalhados sobre o percentual da remuneração de maneira diferente, como pode-se observar na Figura 2.

Figura 2 - Proxy Statement Dupont

STIP PERFORMANCE MEASURES

\begin{tabular}{|c|c|c|c|}
\hline & Metric & Weighting & Rationale for Use \\
\hline Corporate performance & $\begin{array}{l}\text { Operating EPS } \\
\text { (Operating EPS compared to an } \\
\text { internal target (Profit Objective)) }\end{array}$ & $50 \%$ & $\begin{array}{l}\text { Closely aligns stockholder and } \\
\text { executive interests } \\
\text { Provides insight with respect to } \\
\text { ongoing operating results }\end{array}$ \\
\hline $\begin{array}{l}\text { Business unit } \\
\text { performance } \\
\text { Because NEOs work across } \\
\text { all businesses, their payout } \\
\text { factor is based on the total } \\
\text { business performance } \\
\text { compared to aggregate } \\
\text { targets in the two } \\
\text { categories shown to the } \\
\text { right. } \\
\text { Payout factors are } \\
\text { determined separately for }\end{array}$ & 1. Operating earnings & $25 \%$ & $\begin{array}{l}\text { Measures profitability at the business } \\
\text { level leading to corporate EPS results }\end{array}$ \\
\hline $\begin{array}{l}\text { performance compared to } \\
\text { its objective for the year. }\end{array}$ & $\begin{array}{l}\text { 2. Revenue } \\
\text { (Business unit revenue versus } \\
\text { budget for the year) }\end{array}$ & $25 \%$ & $\begin{array}{l}\text { Reflects top-line growth }- \text { critical to } \\
\text { Company success }\end{array}$ \\
\hline Individual performance & Individual performance assessment & Modifier & $\begin{array}{l}\text { The STIP award will be based on } \\
\text { financial performance. Awards earned } \\
\text { based on financial performance may } \\
\text { be adjusted up or down to recognize } \\
\text { individual performance. STIP awards } \\
\text { are capped at } 200 \% \text { of target. }\end{array}$ \\
\hline
\end{tabular}

Fonte: DUPONT (2017)

Como mostra a figura 2, a empresa Dupont evidencia as medidas de desempenho utilizadas na parcela de curto prazo, sendo divididos em desempenho corporativo - $50 \%$ atrelados aos ganhos por ação operacional - e desempenho da unidade de negócios - $25 \%$ atrelado aos ganhos operacionais, $25 \%$ sobre as receitas (receitas da unidade contra o orçamento para o ano). Ainda se nota que a empresa utiliza o desempenho individual como um modificador, podendo ser utilizado para 
ajustar o desempenho financeiro. Outro item, que pode ser mencionado é a razão de uso que a companhia anexou na última coluna da figura acima, que mostra o motivo pelo qual foram utilizados esses indicadores de desempenho.

Quanto a quantidade de indicadores mapeados nos relatórios das empresas, chegou-se a Tabela 3.

Tabela 3 - Quantidade de indicadores por grupo em empresas brasileiras

\begin{tabular}{c|c|c|c|c|c|c}
\hline & $\mathbf{2 0 1 6}$ & $\mathbf{2 0 1 5}$ & $\mathbf{2 0 1 4}$ & $\mathbf{2 0 1 3}$ & TOTAL & Média \\
\hline Ganhos & 35 & 13 & 14 & 15 & 77 & 0,306 \\
EBIT & 52 & 20 & 23 & 18 & 113 & 0,448 \\
Vendas & 31 & 13 & 11 & 7 & 62 & 0,246 \\
Performance Individual & 40 & 28 & 23 & 16 & 107 & 0,425 \\
Objetivos Operacionais & 44 & 17 & 22 & 9 & 92 & 0,365 \\
EVA & 4 & 0 & 3 & 5 & 12 & 0,048 \\
Objetivos Estratégicos & 34 & 10 & 9 & 5 & 58 & 0,230 \\
Satisfação dos clientes & 13 & 6 & 3 & 3 & 25 & 0,099 \\
Preço das ações & 10 & 4 & 4 & 5 & 23 & 0,091 \\
Discricionário & 5 & 1 & 1 & 0 & 7 & 0,028 \\
Segurança & 3 & 1 & 0 & 0 & 4 & 0,016 \\
TOTAL & 271 & 113 & 113 & 83 & 580 & 2,30 \\
MÉDIA & 4,30 & 1,79 & 1,79 & 1,31 &
\end{tabular}

Fonte: Dados da pesquisa (2018)

Observa-se que as empresas brasileiras utilizam, em sua maioria, indicadores ligados diretamente ao desempenho individual de cada executivo e o EBIT que é medido por meio de indicadores globais. Enquanto as empresas brasileiras adotam, em média, 2,3 indicadores por ano, o estudo de Murphy (2001) a média foi de 2,41 por empresa evidenciando quantidade de indicadores próximos.

No entanto, nota-se a disparidade entre 2016 e os anos anteriores. Destaca-se, desta maneira, os indicadores atrelados ao EBIT e aos Objetivos Estratégicos, que subiram vertiginosamente naquele ano. Este aumento pode indicar que as empresas estão construindo pacotes de remuneração mais detalhados, e consequentemente mais indicadores podem ser mapeados, inflando desta forma a quantidade encontrada.

Neste sentido, a empresa brasileira com maior número de indicadores mapeados neste estudo é a Suzano Papel em 2016, com 18 indicadores mencionados para remunerar seus executivos. Destes 18, metade deles são ligados aos objetivos estratégicos da companhia e um terço são relacionados com objetivos operacionais. Na contramão da Suzano, algumas empresas não possuem indicadores para remunerar seus executivos, como por exemplo a Braskem, Copel e Itausa. Ou seja, o maior valor encontrado no estudo foram os 18 indicadores publicados pela Suzano Papel, enquanto que o menor valor foi encontrado em 116 formulários, quase metade dos formulários analisados. Desta forma, é possível constatar que as empresas brasileiras, de um modo geral, têm melhorado a forma como divulgam seus dados. No entanto, ainda pecam em alguns pontos conforme mencionado.

Estes resultados se aproximam de Malvessi e Filho (2016) que observaram que grande parte das empresas utilizam componentes qualitativos para a remuneração variável. Ainda, utilizam indicadores de análise financeira, tais como: Ebitda, Lucro líquido, volume de vendas, custos, EVA, Receita líquida, ROIC, ROI, lucro operacional e retorno total ao acionista.

Ao verificar-se as empresas dos EUA, com relação a quantidade de indicadores mapeados, chega-se a Tabela 4.

Tabela 4 - Quantidade de indicadores por grupo em empresas norte-americanas

\begin{tabular}{c|c|c|c|c|c|c}
\hline & $\mathbf{2 0 1 6}$ & $\mathbf{2 0 1 5}$ & $\mathbf{2 0 1 4}$ & $\mathbf{2 0 1 3}$ & TOTAL & Média \\
\hline Ganhos & 69 & 83 & 83 & 93 & 328 & 2,733 \\
EBIT & 60 & 43 & 37 & 40 & 180 & 1,500 \\
Vendas & 32 & 30 & 30 & 30 & 122 & 1,017 \\
Performance Individual & 8 & 8 & 9 & 8 & 33 & 0,275 \\
Objetivos Operacionais & 6 & 10 & 6 & 5 & 27 & 0,225
\end{tabular}




\begin{tabular}{c|c|c|c|c|c|c}
\hline & $\mathbf{2 0 1 6}$ & $\mathbf{2 0 1 5}$ & $\mathbf{2 0 1 4}$ & $\mathbf{2 0 1 3}$ & TOTAL & Média \\
\hline EVA & 0 & 0 & 0 & 0 & 0 & 0,000 \\
Objetivos Estratégicos & 30 & 26 & 15 & 27 & 98 & 0,817 \\
Satisfação dos clientes & 7 & 3 & 2 & 6 & 18 & 0,150 \\
Preço das ações & 15 & 30 & 33 & 26 & 104 & 0,867 \\
Discricionário & 0 & 0 & 0 & 0 & 0 & 0,000 \\
Segurança & 2 & 3 & 3 & 2 & 10 & 0,083 \\
TOTAL & 229 & 236 & 218 & 237 & 920 & 7,67 \\
MÉDIA & 7,63 & 7,87 & 7,27 & 7,9 &
\end{tabular}

Fonte: Dados da pesquisa (2018)

Nota-se uma grande utilização dos 2 primeiros grupos, onde o grupo de ganhos tem claro destaque, pois aparece em média 2,7 vezes por empresa por ano. Destaca-se ainda a quantidade de indicadores utilizados na média por essas empresas, que soma 7,67 indicadores por ano, enquanto que o Brasil possui uma média de 2,30, ou seja, mais de 3 vezes inferior.

Com relação aos extremos entre a quantidade de indicadores, foi possível observar que a Microsoft é a empresa com mais indicadores mapeados em 2016, com 16. Enquanto isso, a Apple é a com a menor quantidade de indicadores, com 3. Destaca-se, desta forma, que todas as empresas possuem algum indicador mapeado, ao contrário do Brasil, onde boa parte não possui ou não divulgou tal informação.

Esse fato mostra como o mercado americano é maduro na divulgação dos seus pacotes de remuneração. Desta forma, detalha de maneira transparente como cada um dos seus executivos é remunerado.

No que concerne aos grupos de indicadores mencionados, pode-se observar que $34,13 \%$ das empresas possuem algum indicador atrelado ao EBIT, conforme Tabela 5.

Tabela 5 - Percentual de utilização nas empresas brasileiras

\begin{tabular}{c|c|c|c|c|c|c}
\hline $\mathbf{n = 6 3}$ & $\mathbf{2 0 1 6}$ & $\mathbf{2 0 1 5}$ & $\mathbf{2 0 1 4}$ & $\mathbf{2 0 1 3}$ & TOTAL & \% \\
\hline Ganhos & 27 & 12 & 13 & 13 & 65 & $25,79 \%$ \\
EBIT & 38 & 16 & 19 & 13 & 86 & $34,13 \%$ \\
Vendas & 22 & 8 & 7 & 3 & 40 & $15,87 \%$ \\
Performance Individual & 26 & 13 & 13 & 8 & 60 & $23,81 \%$ \\
Objetivos Operacionais & 27 & 7 & 9 & 6 & 49 & $19,44 \%$ \\
EVA & 3 & 0 & 2 & 4 & 9 & $3,57 \%$ \\
Objetivos Estratégicos & 19 & 9 & 6 & 3 & 37 & $14,68 \%$ \\
Satisfação dos clientes & 12 & 6 & 3 & 3 & 24 & $9,52 \%$ \\
Preço das ações & 8 & 4 & 4 & 4 & 20 & $7,94 \%$ \\
Discricionário & 5 & 1 & 1 & 0 & 7 & $2,78 \%$ \\
Segurança & 3 & 0 & 0 & 4 & $1,59 \%$ \\
\hline
\end{tabular}

Fonte: Dados da pesquisa (2018)

Observa-se desta forma que 38 empresas, das 63 analisadas, possuem algum indicador relacionado com EBIT no último ano analisado. Com relação aos Ganhos, das 63 empresas, 27 possuem algum indicador ligado à remuneração

Com essa análise constata-se ainda que apesar de possuir mais indicadores que o subgrupo dos "ganhos", o desempenho individual ainda é considerado por menos empresas que aquele. Isto indica que há maior variedade de indicadores atrelados a performance individual utilizados pelas empresas, conforme identificado na Tabela 3 mencionada, mas o atributo dos ganhos, que é um indicador global, ainda possui maior relevância na remuneração das empresas brasileiras.

Quanto a quantidade de indicadores por empresa, destaca-se que todas elas divulgam a forma como pagam seus executivos e detalham os indicadores, ou seja, nenhuma das empresas deixou de informar esse dado ou não pagam remuneração variável a seus executivos, como no Brasil. No entanto, cabe a ressalva quanto aos indicadores utilizados, conforme Tabela 6: 
Tabela 6 - Percentual de utilização nas empresas norte-americanas

\begin{tabular}{l|l|l|l|l|l|l}
\hline $\mathbf{n = 3 0}$ & $\mathbf{2 0 1 6}$ & $\mathbf{2 0 1 5}$ & $\mathbf{2 0 1 4}$ & $\mathbf{2 0 1 3}$ & TOTAL & $\mathbf{\%}$ \\
\hline Ganhos & 29 & 29 & 29 & 29 & 116 & $96,67 \%$ \\
EBIT & 26 & 20 & 21 & 19 & 86 & $71,67 \%$ \\
Vendas & 21 & 21 & 20 & 21 & 83 & $69,17 \%$ \\
Performance Individual & 28 & 29 & 30 & 29 & 116 & $96,67 \%$ \\
Objetivos Operacionais & 5 & 4 & 4 & 2 & 15 & $12,50 \%$ \\
EVA & 0 & 0 & 0 & 0 & 0 & $0,00 \%$ \\
Objetivos Estratégicos & 12 & 13 & 8 & 13 & 46 & $38,33 \%$ \\
Satisfação dos clientes & 5 & 2 & 3 & 4 & 14 & $11,67 \%$ \\
Preço das ações & 15 & 23 & 25 & 0 & 0 & $69,17 \%$ \\
Discricionário & 0 & 0 & 2 & 1 & $0,00 \%$ \\
Segurança & 2 & 2 & & $5,83 \%$ \\
\hline
\end{tabular}

Fonte: Dados da pesquisa (2018)

Os resultados encontrados estão alinhados com o estudo de Murphy (2001), que observou que aproximadamente $90 \%$ das empresas americanas possuem indicadores ligados ao lucro contábil. Outro estudo realizado com resultado similar foi o realizado por Malvessi e Filho (2016) com empresas brasileiras que mostrou que as empresas utilizaram indicadores vinculados à lucratividade, tais como: lucro líquido, vendas, custos e EBITDA.

Ainda, nota-se que praticamente a totalidade dos EUA utiliza indicadores individuais. Algumas empresas - Chevron, Cisco, Coca-Cola, Merck - utilizam estes indicadores de forma mais ativa, pois atribui o elemento individual como um fator do cálculo da remuneração, enquanto outras companhias apresentam o indicador apenas como um moderador de avaliação. Notou-se que algumas empresas utilizam o desempenho individual apenas como indicador na remuneração fixa, todavia, a maioria utiliza nos pagamentos de incentivos anuais e de longo prazo. No Brasil, este percentual chegou a apenas 23,81\%.

Observou-se ainda que as empresas colocam indicadores subjetivos ligados principalmente aos indicadores individuais. A Cisco, empresa sediada nos EUA, por exemplo, traz indicadores atrelados a liderança, inovação, execução. A Coca-Cola, por sua vez, traz indicadores como: contribuições para iniciativas estratégicas, inclusive nas áreas de Pessoas, Planeta, Produtividade, Parceiros, etc.

Já a BRF, empresa sediada no Brasil, traz indicadores como aderência aos padrões de qualidade de produtos e aderência aos valores da companhia para avaliar individualmente seus gestores. Cabe a ressalva que a BRF misturou indicadores globais e os considerou na análise individual, algo que a Cisco e a Coca-Cola não fizeram. A empresa brasileira utilizou para medição individual do desempenho itens como EBITDA e estabelecimento prévio de metas coletivas. Outro exemplo de como as empresas brasileiras divulgam é a Engie, que menciona apenas que considera nos indicadores individuais o cumprimento de metas e questões comportamentais e gerencias. No entanto não mistura indicadores globais com individuais, como feito pela BRF.

Nota-se ainda também quase todas as empresas adotam indicadores ligados a ganhos, calculados de forma global para todos os executivos. Com relação ao grupo mais relevante, destaca-se a utilização do TSR (Total Stock Return), presente em mais de $80 \%$ das empresas que se utilizam de algum indicador deste grupo. Para o Brasil, o indicador mais presente é o lucro líquido consolidado.

Com relação ao subgrupo EBIT, outra diferença notável é observada. Enquanto que as empresas brasileiras adotam, em sua maioria, indicadores ligados diretamente ao EBITDA, ou seja, diretamente relacionado ao lucro contábil, as empresas dos EUA, por sua vez, utilizam, em sua maioria (aproximadamente 50\%), indicadores ligados ao fluxo de caixa. Esta diferença entre os países da importância que se dá aos indicadores de desempenho pode ser explicada pela Tabela 7.

Tabela 7 - Composição da remuneração Brasil e EUA

\begin{tabular}{c|c|c|c|c|c}
\hline & PAÍS & $\mathbf{2 0 1 6}$ & $\mathbf{2 0 1 5}$ & $\mathbf{2 0 1 4}$ & $\mathbf{2 0 1 3}$ \\
\hline \multirow{2}{*}{ \% Fixa } & BRASIL & $56,42 \%$ & $50,76 \%$ & $49,32 \%$ & $48,99 \%$ \\
& EUA & $16,09 \%$ & $15,08 \%$ & $18,73 \%$ & $14,10 \%$ \\
\% "Variável” & BRASIL & $43,58 \%$ & $49,24 \%$ & $50,68 \%$ & $51,01 \%$ \\
& EUA & $83,91 \%$ & $84,92 \%$ & $81,27 \%$ & $85,90 \%$ \\
\hline
\end{tabular}

Fonte: Dados da pesquisa (2018) 
As remunerações das empresas norte americanas foram evidenciadas na Tabela 7 como segue: valores fixos - salário e benefícios (seguros de vida, plano de saúde e pensão), enquanto a parcela variável inclui os bônus, pagamento por ações, opções de ações.

Pode-se observar na tabela 7, que a parcela de remuneração fixa, em média, foi de 51,37\% (Brasil) e 16\% (EUA) no período analisado. Estes resultados vão de encontro à tendência observada por Machado e Beuren (2015) que, em média, a parcela fixa era de 80,88\% (Brasil) e 37,95\% (EUA) no período de 2007 a 2010. Já a parcela de remuneração variável, em média, foi de 48,63\% (Brasil) e 84\% (EUA). Estes resultados, mostram continuidade com o estudo de Murphy (2013) onde a maior parcela da remuneração está relacionada ao longo prazo. Ademais, no estudo de Machado e Beuren (2015) a parcela variável, em média, era de 19,13\% (Brasil) e 62,05\% (EUA).

Nota-se a discrepância entre a remuneração fixa e variável ou também conhecida como "no risco", pois fazem parte os pagamentos baseados em ação assim como bônus (BALSAM, 2002) e, principalmente, os incentivos de longo prazo mantêm os executivos no risco (ELLIG, 2007). Enquanto que no Brasil praticamente metade da remuneração é fixa, nos EUA esse valor não chega a $20 \%$ em nenhum dos anos da análise. Assim, nota-se que as empresas americanas elaboram seus planos de compensação visando reter os talentos na companhia, remunerando seus executivos com participação elevada em elementos de longo prazo, visto que se identificou que quase a metade da remuneração é atrelada a opção de ações.

Desta forma, é possível constatar que o ambiente externo, atrelado ao mercado acionário, acaba tendo papel decisivo na remuneração deste pessoal. Já no Brasil, estes valores acabam não sendo tão representativos quanto os valores fixos, que estimulam o comodismo dos diretores, conforme Balsam (2002) e Kolb (2012) ao citarem a motivação proporcionada por pacotes de remuneração bem feitos para que os executivos possam buscar melhores remunerações e com a consequente valorização da empresa no mercado. Este pensamento também é corroborado por Jensen e Murphy (2010) ao afirmarem que as empresas, para se destacarem entre seus pares, buscam executivos que corram maiores riscos sendo consequentemente mais criativos.

Por fim, destaca-se que, enquanto é possível verificar nas empresas americanas informações sobre os indicadores de curto prazo e longo prazo, no Brasil tal análise não é possível dado que o conteúdo que as empresas trazem em seus formulários de referência é insuficiente para levantar esta informação.

\section{CONCLUSÕES}

O estudo objetivou demonstrar como as empresas sediadas nos Estados Unidos da América e do Brasil utilizam os indicadores de desempenho para remunerar seus executivos, assim como atrelá-los nos pagamentos de curto e longo prazo.

Notou-se que não há um padrão na escolha das medidas de desempenho pelas empresas. Diversas características devem ser consideradas na elaboração de um contrato de remuneração baseado em incentivos. Como aponta Baker et al. (1994) cuja efetividade depende de um conjunto de fatores sociais, psicológicos e econômicos.

Observou-se a grande diferença entre os formulários de referência (Brasil) e as Proxy Statements (EUA), no que diz respeito às informações divulgadas sobre os pacotes de remuneração, principalmente, os indicadores de desempenho utilizados. Esta discrepância pode ser explicada pelo tempo que ambos os mercados vêm divulgando tais informações. Os EUA divulgam desde 1938, enquanto o Brasil passou a divulgar a partir de 2009 (BEUREN; SILVA, 2015).

Pode-se notar que as empresas norte americanas divulgam com maior quantidade e qualidade informacional, além de terem sua remuneração mais voltada ao longo prazo, dado este que não é possível de verificar no Brasil. No entanto, dado a baixa remuneração atrelada a opção de ações das empresas brasileiras, pode-se inferir que não há tanto enfoque nessa remuneração.

Destaca-se que as empresas divulgam os dados e a remuneração dos executivos de forma segregada e detalhada, mostrando o quanto cada executivo recebe de forma fixa, variável, em valor monetário ou em ações. Em contrapartida, as empresas brasileiras não divulgam as informações, principalmente, relativas às remunerações de forma segregada, apenas informam o valor global do quanto foi destinado para cada diretoria. Para efeito de análise, houve algumas limitações na medida em que seria pertinente a segregação da remuneração entre o CEO e os demais executivos, uma vez que aquele, algumas vezes, recebe valores atrelados ao desempenho maiores que os demais, além de ser o principal responsável pelas decisões.

Em relação as medidas de desempenho no Brasil, pode-se observar que poucas empresas divulgam a informação como a empresa Cemig que informa de maneira objetiva, mas informa. Por outro lado, nos EUA, a maioria das empresas divulgam como a Home Depot (figura 1), onde evidenciam a composição dos pacotes de remuneração, assim como os indicadores e suas respectivas porcentagens, mostrando ainda os limiares, alvos e máximos da compensação a ser recebida. Adicionalmente, as empresas norte-americanas utilizam indicadores baseados em grupos, onde analisam os resultados e indicadores de um grupo de empresas, e assim comparam com seu desempenho. Estratégica essa não abordada nos formulários analisados no mercado nacional.

Quanto a utilização dos indicadores ao longo do tempo, notou-se que as empresas sediadas nos EUA mostram definir melhor quantos e quais indicadores utilizam no curto e longo prazo. Para as empresas sediadas no Brasil, no geral, não se pode afirmar como os indicadores são utilizados no curto e longo prazo, dificultando assim uma comparação entre países. Além disso, deixam mais claro quais indicadores estão utilizando, especialmente quanto aos indicadores 
subjetivos, que algumas empresas evidenciam de forma mais transparente, como a Coca-Cola, por exemplo, que inclui inclusive o alcançado por cada executivo. No entanto, de um modo geral, as empresas precisam melhorar esse conjunto de informações divulgadas.

Como limitação, destaca-se que o estudo não entrou no mérito de regulamentação das remunerações de executivos, assim como dos benefícios fiscais que cada tipo de remuneração possui sobre os resultados das companhias. Desta forma, não pode ser utilizado para determinar fatores institucionais que podem afetar as remunerações dos executivos em cada um dos países.

Para estudos futuros sugere-se a análise aprofundada das empresas levando em consideração as características consideradas essenciais pelos autores, podendo ser separadas por setores, ou menor período de análise. Outra possibilidade é a comparação com países mais próximos da realidade brasileira. Desta forma, poderia se verificar se a forma brasileira de divulgação está seguindo a linha de algum outro país pelo globo.

\section{REFERÊNCIAS}

ABERNETHY, Margaret A.; BOUWENS, Jan; VAN LENT, Laurence. The Role of Performance Measures in the Intertemporal Decisions of Business Unit Managers. Contemporary Accounting Research, , v. 30, n. 3, p. 962-969, 2013.

AGRAWAL, Anup; MANDELKER, Gershon N. Managerial Incentives and Corporate Investment and Financing Decisions. The Journal of Finance, v. 42, n. 4, p. 823-837, 1987.

AGUIAR, Andson Braga De; PIMENTEL, Renê Coppe. Remuneração de Executivos e Desempenho no Mercado Brasileiro : Relações Contemporâneas e Defasadas. Revista de Administração Contemporânea, v. 21, n. 4, p. 545-568, 2017.

ARCOVERDE, Letícia. Falta equilibrio na estratégia de remuneração variávelValor Econômico. São Paulo, 2017. Disponível em: <https://www.valor.com.br/carreira/4964678/falta-equilibrio-na-estrategia-de-remuneracao-variavel>. Acesso em 23 jul. 2018.

BAKER, George; GIBBONS, Robert; MURPHY, Kevin J. .. Subjective Performance Measures in Optimal Incentive Contracts. The Quarterly Journal of Economics, v. 109, n. 4, p. 1125-1156, 1994.

BAKER, George P.; JENSEN, Michael C.; MURPHY, Kevin J. Compensation and Incentives : Practice vs . Theory. THE JOURNAL OF FINANCE, v. XLIII, n. 3, p. 593-616, 1988.

BALSAM, Steven. An Introduction to Executive Compensation. Academic Press, 2002.

BEBCHUK, Lucian Arye; FRIED, Jesse M. Pay without Performance: The Unfulfilled Promise of Executive Compensation. Harvard University Press, 2004.

BENNETT, Benjamin et al. Compensation goals and firm performance. Journal of Financial Economics, v. 124, n. 2, p. 307330, 2017

BEUREN, Ilse Maria; SILVA, Júlio Orestes Da. Evidenciação da remuneração variável dos executivos nas maiores empresas brasileiras listadas na BM \& FBovespa Disclosure of variable remuneration of executives by the major brazilian companies listed in BM \& FBovespa. Enfoque: Reflexão Contábil, v. 34, n. 3, p. 95-124, 2015.

BOYD, Brian K. Determinants of US Outside Director Compensation. Corporate Governance: An International Review, v. 4, n. 4, p. 202-211, 1996.

CONYON, Martin J. Executive Compensation and Board Governance in US Firms. The Economic Journal, v. 124, n. 574, p. 60-89, 2014.

CONYON, Martin J.; HE, Lerong. Executive Compensation and Corporate Governance in China. Journal of Corporate Finance, v. 17, n. 4, p. 1158-1175, 2011.

DALMACIO, Flavia Zoboli; REZENDE, Amaury Jose; SLOMSKI, Valmor. Análise Setorial Das Medidas De Performance Utilizadas Nos Contratos De Remuneração Dos Gestores. Revista Universo Contábil, v. 5, n. 3, p. 6-23, 2009.

EDMANS, Alex; GABAIX, Xavier. Is CEO pay really inefficient? A survey of new optimal contracting theories. European Financial Management, v. 15, n. 3, p. 486-496, 2009.

ELLIG, Bruce R. The Complete Guide to Executive Compensation.: McGraw-Hill, 2007.

ELY, Kirsten M. Interindustry Differences in the Relation Between Compensation and Firm Performance Variables. Journal of Accounting Research, v. 29, n. 1, p. 37-58, 1991.

FARID, Mamdough; CONTE, Vincent; LAZARUS, Harold. Toward a general model for executive compensation. Journal of Management Development, v. 30, n. 1, p. 61-74, 2011.

FERNANDES, Francisco Carlos; MAZZIONI, Sady. A correlação entre a remuneração de executivos e o desempenho das empresas brasileiras do setor financeiro. Revista Contabilidade Vista \& Revista, v. 26, n. 2, p. 41-64, 2015.

FRANTZ, Pascal; INSTEFJORD, Norvald; WALKER, Martin. Executive compensation: A model of disclosure choice. Journal of Business Finance and Accounting, v. 40, n. 9-10, p. 1184-1220, 2013.

FUNCHAL, Jéferson de Araújo; TERRA, Paulo Renato Soares. Remuneração de Executivos, Desempenho Econômico e Governança Corporativa: um Estudo Empírico em Empresas Latino-Americanas. Salvador

HALL, Brian J. A better way to pay CEOs? In: CARPENTER, Jennifer; YERMACK, David (Eds.). Executive Compensation and Shareholder Value: Theory and Evidence. Springer, v. 4p. 35-46, 1999. 
HALL, Brian J.; LIEBMAN, Jeffrey B. Are CEOs really paid like bureaucrats? The Quarterly Journal of Economics, v. 113, n. 3, p. 653-691, 1998 .

IBRAHIM, Salma; LLOYD, Cynthia. The association between non-financial performance measures in executive compensation contracts and earnings management. Journal of Accounting and Public Policy, v. 30, n. 3, p. 256-274, 2011.

ITTNER, Christopher D.; LARCKER, David F.; RAJAN, Madhav V. The Choice of Performance Measures in Annual Bonus Contracts. The Accounting Review, v. 72, n. 2, p. 231-255, 1997.

JENSEN, Michael C.; MECKLING, William H. Theory of the Firm : Managerial Behavior , Agency Costs and Ownership Structure. Journal of Financial Economics, v. 3, n. 4, p. 305-360, 1976.

JENSEN, Michael C.; MURPHY, Kevin J. CEO Incentives - It's Not How Much You Pay, But How. Journal of Applied Corporate Finance, v. 22, n. 1, p. 64-77, 2010.

JENSEN, Michael C.; MURPHY, Kevin J.; WRUCK, Eric G. Remuneration: Where We've Been, How We Got to Here, What are the Problems, and How to Fix ThemHarvard Business School NOM Research Paper: Finance. Disponivel em: <http:// www.ssrn.com/abstract $=561305>$.

KOLB, Robert W. Too much is not enough: Incentives in executive compensation. Oxford University Press, 2012.

KRAUTER, Elizabeth. Remuneração de Executivos e Desempenho Financeiro: um Estudo com Empresas Brasileiras. Revista de Educação e Pesquisa em Contabilidade, v. 7, n. 3, p. 259-273, 2013.

LAKSMANA, Indrarini. Corporate Board Governance and Voluntary Disclosure of Executive Compensation Practices. Contemporary Accounting Research, v. 25, n. 4, p. 1147-82, 2008.

LAMBERT, Richard A.; LARCKER, David F. An Analysis of the Use of Accounting and Market Measures of Performance in Executive Compensation Contracts. Journal of Accounting Research, v. 25, p. 85-125, 1987.

MACHADO, Débora Gomes; BEUREN, Ilse Maria. Política de remuneração de executivos: um estudo em empresas industriais brasileiras, estadunidenses e inglesas. Gestão \& Regionalidade, v. 31, n. 92, p. 1-16, 2015.

MALVESSI, Oscar Luiz; FILHO, JOÃO LINS PEREIRA. Remuneração Executiva e o impacto na Geração de Valor. Revista de Finanças e Contabilidade da Unimep, v. 3, n. 1, p. 37-49, 2016.

MARÍN, Gregorio Sánchez; SÁNCHEZ, Antonio Aragón. Top Managers' Compensation, Strategic Orientations, and Firm Performance: Enpirical Evidence from Spanish Firms. Management Research, v. 1, n. 1, p. 27-44, 2003. 2001.

MURPHY, Kevin J. Perfonnance standards in incentive contracts. Journal of Accounting and Economics, v. 30, p. 245-278,

MURPHY, Kevin J. Executive Compensation: Where We Are, and How We Got There. Em: Handbook of the Economics of Finance, v. 2, p. 211-356, 2013.

REICHELSTEIN, Stefan. Providing Managerial Incentives : Cash Flows versus Accrual Accounting. Journal of Accounting Research, v. 38, n. 2, p. 243-269, 2000.

SCHIEHLL, Eduardo; TERRA, Paulo Renato Soares; VICTOR, Fernanda Gomes. Determinants of voluntary executive stock option disclosure in Brazil. Journal of Management \& Governance, v. 17, n. 2, p. 331-361, 2011.

SINGH, Satwinder; DARWISH, Tamer K.; POTOČNIK, Kristina. Measuring Organizational Performance: A Case for Subjective Measures. British Journal of Management, v. 27, n. 1, p. 214-224, 2016.

SLOAN, Richard G. Accounting earnings and top executive compensation. Journal of Accounting and Economics, v. 16, p. $55-100,1993$

ZÁBOJNÍK, Ján. Subjective evaluations with performance feedback. RAND Journal of Economics, v. 45, n. 2, p. 341-369, 2014. 